\title{
Tradução via música: os cantos de Marie Tudor e Ruy Blas
}

\author{
Mateus Roman Pamboukian*
}

\section{O caso da canção de Marie Tudor}

Em 1885, ano do desaparecimento de Victor Hugo, a Imprensa Nacional publica a antologia Hugonianas, organizada por Múcio Teixeira. A exemplo das Lamartineanas ${ }^{1}$, antologia que aparecera dezesseis anos antes por ocasião da morte de Alphonse de Lamartine (1869), trata-se de uma coletânea de poemas de Victor Hugo traduzidos por poetas brasileiros. A recolha reúne versões poéticas assinadas por dezenas de poetas-tradutores diferentes, das quais "55 versões extraídas de vários livros e jornais, e 51 traduções feitas expressamente para a [...] coleção" 2 (TEIXEIRA, 1885, p. 483). Entre os poetas-tradutores das Hugonianas, há desde figuras hoje mergulhadas em relativa ou completa obscuridade (como os jornalistas Salustiano Sebrão e Fontoura Xavier, o juiz Manoel Victor Fernandes Barros e o médico e latinista Castro Lopes, este último lembrado principalmente por sua militância contra estrangeirismos e pela invenção do termo "ludopédio" 3 ) a autores centrais do romantismo brasileiro (Gonçalves Dias, Castro Alves, Casemiro de

\footnotetext{
${ }^{*}$ Universidade de São Paulo (USP).

${ }^{1} \mathrm{O}$ próprio organizador da antologia admite a influência da coletânea anterior: "A ideia, que determinou o aparecimento deste livro, não é original minha, por dois motivos: além de me ser lembrada por meu amigo e primeiro romancista brasileiro da atualidade, Dr. Escragnolle Taunay, com quem Joaquim Serra e eu nos achávamos, na Livraria Faro \& Nunes, quando chegou a notícia do trespasso de Victor Hugo, nessa mesma ocasião, e a propósito disso, lembrámo-nos de homenagem idêntica, que, pouco depois do falecimento de Lamartine, foi consagrada à memória do suavíssimo poeta do Jocelyn. Refiro-me às Lamartineanas, traduções também de poetas brasileiros, colecionadas pelo Dr. Macedo Soares" (TEIXEIRA, 1855, p. 473).

${ }^{2}$ A relação de Múcio Teixeira ("55 versões" e "51 poemas", 106 textos no total) contradiz o índice da antologia, no qual são listados 107 poemas. Além disso, há uma versão extra de Generino dos Santos recolhida em apêndice.

${ }^{3}$ Ver MONTES, 2017.
} 
Abreu). Assim, parecem se confirmar as palavras de Tavares Bastos: "Vicejou de tal modo, no tempo do Império, o hábito das versões poéticas, que deixar de fazê-las era então motivo de geral estranheza" (TAVARES BASTOS, 1952, p. 5).

O jornal Diário Português de 14 de agosto de 1885 assim descreveu o florilégio lançado em homenagem ao poeta francês:

\begin{abstract}
O livro é uma coletânea de poesias de Hugo, trasladadas a português pelos mais notáveis poetas do Brasil, e das quais algumas são cinzeladamente trabalhadas, escrupulosamente fiéis, observando a forma límpida, original e vibrante do mestre, sem desmerecer na sonoridade orquestrante das rimas e na pompa fulgente das imagens. [...] Não será indiscrição, parecenos, dizer que a publicação foi feita sob os auspícios da Sua Majestade, o Imperador, que para si reivindica um soberbo título de glória, impulsionando a arte que esmorece, mercê da indiferença popular e do acovardamento fundamentado dos editores. (HUGONIANAS, 1885, p. 3)
\end{abstract}

Embora se trate inequivocamente de uma recolha de poesia (o subtítulo da obra é "Poesias de Victor Hugo traduzidas por poetas brasileiros"), a antologia de Múcio Teixeira também reúne traduções em verso de dois fragmentos de romances (de Bug-Jargal: "Canção de BugJargal" de Gonçalves Dias; de Notre-Dame de Paris: "Canção de Quasímodo" de Generino dos Santos) e diversos fragmentos de peças (Hernani, Marion Delorme, Le Roi s'amuse, Marie Tudor, Ruy Blas etc $)$. Curiosamente, Teixeira recolheu três traduções de um mesmo trecho em verso de Marie Tudor (peça predominantemente em prosa): "Canção" de Félix da Cunha, "Canção" de Amália Figueiroa e "Serenata" de Rozendo Moniz. Em Portugal, o mesmo trecho foi traduzido pelo poeta e pedagogo português João de Deus, também sob o nome de "Canção" (não recolhido nas Hugonianas):

\footnotetext{
${ }^{4}$ Ver TAVARES BASTOS, 1952, p. 33.
} 
(Victor Hugo)

On entend une guitare et une voix éloignée qui chante :

Quand tu chantes, bercée

Le soir entre mes bras,

Entends-tu ma pensée

Qui te répond tout bas?

(HUGO, 1955, p. 43)
(Rozendo Moniz)

Serenata

Quando cantas embalada

À noite, nos braços meus

Não ouves? Meus pensamentos

Respondem baixinho aos teus.

(TEIXEIRA, 1885 , p. 220)

(João de Deus)

Canção

Mulher, quando em meus braços

Nos meus braços embalada, Te escuto uma canção

Entendes meu pensamento

Que te responde, adorada?

Não vês nos meus abraços

Profunda comoção?

(MAGALHÃES JR., 1950, p.150)

(TEIXEIRA, 1885, p. 19)

Além de os títulos dos poemas divergirem (Rozendo Moniz adota o título "Serenata"), dois outros aspectos chamam a atenção: em primeiro lugar, que um singelo poemeto "escondido" no primeiro ato de uma peça em prosa fosse tão conhecido e suscitasse tantas versões em português; em segundo lugar, o fato de que João de Deus tenha traduzido apenas as três primeiras estrofes da canção de Marie Tudor, suprimindo as duas estrofes finais. O que estaria por trás de tais escolhas?

Nossa hipótese, avançada em nossa dissertação de mestrado, é que a chave para todas essas questões reside na música: 


\begin{abstract}
As divergências entre títulos e recortes dos versos das traduções lusófonas, assim como a estranha popularidade do trecho, aparentemente são explicadas pelo fato de que ele foi musicado parcialmente por Charles Gounod em 1857, sob o título de Serenade. (PAMBOUKIAN, 2019, p. 17)
\end{abstract}

Assim, é plausível que João de Deus tenha se baseado no texto da canção de Gounod, que também suprime as duas últimas estrofes da canção de Marie Tudor. Da mesma forma, é razoável supor que o título divergente adotado por Rozendo Moniz ("Serenata") se deva ao nome da canção de Gounod ("Serenade"), embora o autor baiano tenha traduzido a canção integralmente. Quanto a Amália Figueroa e Félix da Cunha, conquanto não haja sinais evidentes de que suas traduções tenham sido diretamente intermediadas pela versão musicada, não nos parece despropositado assumir que a canção de Gounod, que parece ter sido conhecida de um certo meio letrado, tenha contribuído para celebrizar o fragmento da peça, tornando-o um texto digno de ser traduzido e inserido em antologias. Isso suscita uma série de questões ainda não respondidas no percurso de nossa pesquisa: de que forma peças musicais como a "Serenade" de Gounod circularam nos meios letrados do Brasil oitocentista? (Se por partituras importadas, por execuções em saraus, por montagens teatrais de Marie Tudor que tenham incluído a versão musicada etc.) Qual foi a extensão do fenômeno das versões poéticas "intermediadas" pela música e seu papel na recepção de autores estrangeiros entre nós? Terá ocorrido com textos de outros autores além de Victor Hugo? Quais foram as condições de circulação de tais versões poéticas?

Embora estejamos longe de responder a todas essas perguntas de forma categórica (trata-se de pesquisa em andamento), uma pista importante para nossa investigação é uma observação feita por Antonio Candido a respeito da formação do público do sistema literário brasileiro:

\footnotetext{
Note-se, também, que prosseguiu por todo do século XIX, e até o início do século XX, a tradição do auditório (ou que melhor nome tenha), graças não apenas à grande voga do discurso em todos os setores da nossa vida, mas, ainda, ao recitativo e à musicalização dos poemas. Foram estas as maneiras principais de veicular a poesia - tanto a dos poetas oficiais, como Magalhães ou Porto-Alegre, quanto a dos irregulares, como Laurindo Rabelo ou
} 


\begin{abstract}
Aureliano Lessa. Se as edições eram escassas, a serenata, o sarau e a reunião multiplicavam a circulação do verso, recitado ou cantado. Desta maneira, românticos e pós-românticos penetraram melhor na sociedade, graças a públicos receptivos de auditores. (CANDIDO, 2019, p. 94)
\end{abstract}

\title{
2. O caso da canção de Ruy Blas
}

Além das três versões da canção de Marie Tudor, a antologia de Teixeira inclui outra tradução de fragmento de drama que parece ter sido intermediada por uma versão musicada, conforme procuraremos demonstrar. Trata-se da "Canção das Lavadeiras", de Souza Pinto, retirada da primeira cena do segundo ato de Ruy Blas:

\begin{tabular}{|c|c|}
\hline Victor Hugo & Souza Pinto \\
\hline À quoi bon entendre & Por que ouvirmos nós \\
\hline Les oiseaux des bois? & As aves da espessura? \\
\hline L'oiseau le plus tendre & Ave mais terna e pura \\
\hline Chante dans ta voix. & Canta na tua voz. \\
\hline Que Dieu montre ou voile & Que mostre ou vele Deus \\
\hline les astres des cieux! & A esfera rutilante \\
\hline La plus pure étoile & A estrela mais brilhante \\
\hline brille dans tes yeux. & Fulge nos olhos teus \\
\hline Qu'avril renouvelle & Que em florida estação \\
\hline Le jardin en fleur! & Brote no prado a rosa. \\
\hline La fleur la plus belle & Mais bela flor mimosa \\
\hline Fleurit dans ton cœur. & Te sai do coração. \\
\hline Cet oiseau de flamme, & Essa ave toda ardor, \\
\hline Cet astre du jour, & Esse astro que irradia, \\
\hline Cette fleur de l'âme, & D'alma a flor que inebria \\
\hline S'appelle l'amour! & É tudo isso o amor! \\
\hline (HUGO, 1839, p. 56) & (apud TEIXEIRA, 1885, p. 223) \\
\hline
\end{tabular}


Assim como a serenata de Marie Tudor, que se ouve no fundo da cena entoada por uma "voix eloignée", uma voz afastada5", a canção de Ruy Blas, introduzida na cena por uma rubrica que indica um "chant eloigné", um "canto afastado" ${ }^{6}$, é atribuída a uma indefinida "voix du dehors", uma voz de fora, que Casilda esclarece ser o canto das lavadeiras:

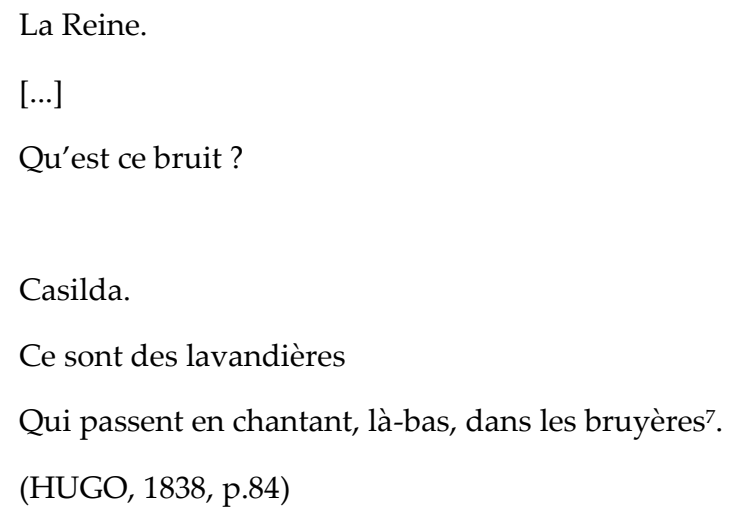

Tanto em Marie Tudor quanto em Ruy Blas, a cena é invadida por cantos que a perturbam. A continuidade dramática é interrompida por essas vozes - não mais interiores, como no título da obra de 1837 (Les Voix Intérieures), mas exteriores. A descontinuidade que a irrupção desses cantos instaura é marcada em termos formais: em Marie Tudor, peça escrita em prosa, a serenata se destaca da ação pelos próprios expedientes da versificação (métrica, rima etc); já em Ruy Blas, peça versificada em alexandrinos com rimas emparelhadas, é o uso de outra estrutura metrorrímica (versos pentassílabos, rimas intercaladas) que marca, do ponto de vista formal, a separação da canção do restante do texto. Essa descontinuidade formal corresponde a uma descontinuidade diegética, que diz respeito à passagem da fala para o canto. No entanto, tais marcações textuais de descontinuidade diegética só são possíveis enquanto a peça

\footnotetext{
5 “On entend une guitare et une voix éloignée qui chante." ["Ouvem-se uma guitarra e uma voz afastada que canta."] HUGO, 1955, p. 23).

6 "On entend au dehors un chant éloigné." ["Ouve-se no exterior um canto afastado."] (HUGO, 1838, p. 84).

7 "A Rainha: que é esse barulho? Casilda: são lavadeiras, que passam cantando, ali, nas urzes" (tradução nossa).
} 
permanece na condição texto escrito; numa representação em cena, é impossível indicar a passagem da fala para o canto pela fria letra de rubricas; assim, é provável que as canções de Marie Tudor e Ruy Blas fossem efetivamente cantadas pelos atores.

Talvez por isso, bem como por suas qualidades textuais, canções como as de Marie Tudor e Ruy Blas constituíram matéria-prima preciosa para compositores. Segundo levantamento feito pelo site LiederNet Archive (EZUST, 2014), o fragmento de Ruy Blas foi musicado por Spohr ("À la bien aimée", 1839), Massé ("La Chanson des Lavandières", 1861), Chabrier ("Ruy Blas", 1866), Delibes ("Sérénade de Ruy-Blas", 1879), Nevin ("La Chanson des Lavandières", 1889), Pilati ("Ruy Blas: Chant des Lavandières", ano não identificado), Saint-Saëns ("À quoi bon entendre les oiseaux des bois?", 1868), Rubinstein ("Liebeswunder", 1879) e Weckerlin ("Sérénade tirée de Ruy Blas", sem ano identificado), além de adaptações em alemão musicadas por Mendelssohn, Spohr e Frank Van der Stucken. Note-se que o título da tradução de Souza Pinto para a canção de Ruy Blas ("Canção das Lavadeiras") é uma tradução literal do título da peça de Massé ("Chanson des Lavandières"), publicada em 1861. Assim como no caso da canção de Marie Tudor, é bastante provável que a tradução de Souza Pinto tenha sido mediada pelo contato com a peça musical. Dessa forma, "o texto se torna música antes de ser reconvertido em texto, passando de fragmento de drama a poema autônomo" (PAMBOUKIAN, 2019, p. 18).

É de se destacar que o texto da canção de Ruy Blas, especialmente por ter servido de base a tantas peças de música erudita, continua suscitando traduções: o site LiederNet Archives (EZUST, 2014) inclui traduções recentes para o espanhol (2007) e inglês (2016). No entanto, trata-se de traduções de outra natureza, cujo objetivo é mais a explicitação do plano do conteúdo do que a recriação de efeitos poéticos. Nesse sentido, a proprietária do site, que detém copyrights sobre a tradução da canção feita por ela para o inglês, permite que suas traduções sejam "reproduzidas sem permissão prévia apenas para programas impressos (não online) de concertos gratuitos" (EZUST, 2014, tradução nossa ${ }^{8}$ ). A título de exemplo, reproduzimos as

\footnotetext{
8 "Emily Ezust permits her translations to be reproduced without prior permission for printed (not online) programs to free-admission concerts only [...]."
} 
primeiras estrofes das traduções para o inglês e espanhol, feitas por Emily Ezust e Alberto Bonati.

\begin{tabular}{|ll|}
\hline Emily Ezust & Alberto Bonati \\
Why should one listen & ¿Para qué escuchar \\
To the birds of the wood? & Las aves del bosque? \\
The most tender bird & El ave más tierna \\
Sings in your voice. & Canta en tu voz. \\
& \\
Let God reveal or hide & ¿Que Dios muestre u oculte \\
The stars in the sky! & Los astros del cielo! \\
The most pure star & La más pura estrella \\
Shines in your eyes. $[\ldots]$ & Brilla en tus ojos. [...] \\
(EZUST, 2014) & (EZUST, 2014b) \\
\hline
\end{tabular}

Em que pese a diferença de natureza das traduções-poemas das Hugonianas e as traduções ancilares disponíveis no site LiederNet Archives, nos dois casos a tradução é mediada pela música; nos dois casos, o processo de transformação textual, que termina com a passagem de um fragmento teatral para textos de outra espécie, é precedido por uma mudança de mídia.

\section{Victor Hugo: um comportamento antimusical?}

Dentre os autores brasileiros, cabe a João Cabral de Melo Neto a fama de poeta avesso à música ${ }^{9}$. Na França, reputação semelhante parece recair sobre o autor de Les Misérables:

Como se observa pelo que se disse até aqui sobre a formação artística de Hugo, apenas uma arte não era muito apreciada pelo autor: a música. Inúmeros estudiosos de Hugo atuais ou não (GLACHANT, 1902; LASTER, 2002; FOUQUET, 2002) afirmam que o escritor não se contentava com um lugar subalterno para a poesia e, por conta disso, seguia uma tradição de

\footnotetext{
9 "Sempre fui antimusical, e na minha adolescência essa postura era incompatível com a poesia. No colégio, tinha um imenso enjoo dos versos tipo 'Ora, direis, ouvi estrelas', com esse ritmo chatíssimo (apud SECHIN, 1999. p. 326).
} 
escritores franceses que consideravam que só se cantava o que não merecia ser dito. (REIS, 2019, p.36)

Curiosamente, no entanto, ao menos num nível diegético, o motivo da canção é recorrente na obra ficcional de Victor Hugo ${ }^{10}$. Além dos casos de Marie Tudor e Ruy Blas, a antologia de Múcio Teixeira recolhe traduções de dois "cantos" extraídos dos romances Bug-Jargal e Notre-Dame de Paris: "Canção de Bug-Jargal", de Gonçalves Dias, e "Canção de Quasímodo", de Generino dos Santos.

Sobre o primeiro texto, que abre a antologia, o organizador se limita à referência sumária: “Esta tradução acha-se a pp. 613-616 da 2ª edição dos Cantos de Gonçalves Dias (Leipzig, F. A. Brockhaus, 1857) e não tem designação de autor" (TEIXEIRA, 1885, p.474). O texto-fonte é um fragmento situado no sétimo capítulo do romance. Assim como nos outros casos, as personagens são surpreendidas por uma canção distante que perturba a continuidade discursiva e instaura um texto dentro do texto. Assim como em Marie Tudor, a canção é acompanhada por um instrumento de cordas (guitarre):
À peine avions-nous pris place, que Marie mit son doigt sur ma bouche ; quelques sons, affaiblis par le vent et par le bruissement de l'eau, venaient de frapper son oreille. J'écoutai ; c'était le même prélude triste et lent qui la nuit précédente avait éveillé ma fureur. Je voulus m'élancer de mon siège, un geste de Marie me retint.
- Léopold, me dit-elle à voix basse, contiens-toi, il va peut-être chanter, et sans doute ce qu'il dira nous apprendra qui il est.
En effet, une voix dont l'harmonie avait quelque chose de mâle et de plaintif à la fois sortit un moment après du fond du bois, et mêla aux notes graves de la guitare une romance espagnole, dont chaque parole retentit assez profondément dans mon oreille pour que ma mémoire puisse encore aujourd'hui en retrouver presque toutes les expressions.
« Pourquoi me fuis-tu, Maria? pourquoi me fuis-tu, jeune fille? pourquoi cette terreur qui glace ton âme quand tu m'entends. ? Je suis en effet bien

\footnotetext{
${ }^{10}$ Quanto à suposta antimusicalidade de Victor Hugo, pondera Patrick Besnier: « Des réticences de Victor Hugo devant l'adaptation de ses œuvres à l'opéra, on a longtemps conclu à une hostilité chez lui, alors qu'il s'intéressait beaucoup à la musique, qu'il faisait d'ailleurs intervenir abondamment dans ses drames. » (BERNIER, 2002, p.50)
} 
formidable ! je ne sais qu'aimer, souffrir et chanter !11 [...] » (HUGO, 1910, p. 392-393)

No entanto, há uma diferença fundamental entre a serenata da personagem Bug-Jargal e as canções de Marie Tudor e Ruy Blas: trata-se de uma espécie de prosa poética, sem os procedimentos tradicionais de métrica e rima. A ausência de cantabilità do texto em prosa é justificada por um artifício cervantino em nota de rodapé: o texto em francês apresentado ao leitor seria apenas uma tradução feita pelo narrador Léopold de um "romance espanhol": "Julgou-se inútil reproduzir aqui as palavras integrais do canto espanhol: ¿Por qué me huyes, Maria? etc." (HUGO, 1910, p. 393, tradução nossa $\left.{ }^{12}\right)$. Assim, a tradução de Gonçalves Dias, publicada em meio a poemas autorais em Últimos Cantos (1851) e posteriormente recolhida por Múcio Teixeira nas Hugonianas, restaura a cantabilità ao canto do escravo-rei Bug-Jargal ao recriá-lo como poema em sentido estrito ${ }^{13}$ :

\footnotetext{
11 "Mal tínhamos ocupado os nossos lugares, Maria pôs o seu dedo na minha boca; alguns sons, enfraquecidos pelo vento e pelo murmúrio da água, acabavam de lhe ferir o ouvido. Escutei; era o mesmo prelúdio triste que na véspera à noite tinha despertado o meu furor. Quis levantar-me da cadeira; um gesto de Maria deteve-me.

- Leopoldo - disse-me ela baixo - domina-te. Ele naturalmente vai cantar, e com certeza poderemos saber quem é.

Com efeito, uma voz harmoniosa, varonil e lamentosa ao mesmo tempo, saiu um momento depois do fundo do bosque e juntou às notas graves da viola uma romanza espanhola de que cada palavra feriu tão profundamente o meu ouvido que a memória ainda hoje pode encontrar quase todas as suas expressões. 'Para que me foges, Maria? Por que me foges, menina? Por que este terror quando me ouves? Sou assim tão horroroso? Sei amar, sofrer e cantar! [...]" (HUGO, 1947, p. 30-31, tradução de Bezerra de Menezes Neto).

12 "On a jugé inutile de reproduire ici en entier les paroles du chant espagnol : Porque me huyes, Maria? etc."

${ }^{13}$ Para uma análise técnica mais detida da tradução-poema de Gonçalves Dias, ver PAMBOUKIAN, 2019.
} 
« Pourquoi me fuis-tu, Maria? pourquoi me fuis-

tu, jeune fille? pourquoi cette terreur qui glace ton âme quand tu m'entends. ? Je suis en effet bien formidable! je ne sais qu'aimer, souffrir et chanter!

«Lorsque, à travers les tiges élancées des cocotiers de la rivière, je vois glisser ta forme légère et pure, un éblouissement trouble ma vue, ô Maria ! et je crois voir passer un esprit! $[\ldots]$
Maria, por que me foges,

Por que me foges, donzela?

Minha voz! o que tem ela,

Que te faz estremecer;

Tão temível sou acaso?

Sei amar, cantar, sofrer.

E quando através dos troncos

Descubro de altos coqueiros

Junto às margens dos ribeiros

A sombra tua a vagar;

Julgo ver passar um anjo

Que os meus olhos faz cegar. [...]

(HUGO, 1910, p. 392)

(DIAS, 2016, p.87)

O segundo "canto" extraído de romance, "Canção de Quasímodo", não está incluído no corpo das Hugonianas, aparecendo apenas nas notas finais da antologia: "Do meu amigo GENERINO DOS SANTOS apenas vão três traduções no corpo desta obra, visto a quarta ter chegado já tarde. Recolho-a, porém, nesta nota, visto ser uma das produções mais curiosas de V. Hugo" (TEIXEIRA, 1885, p. 485).

Quelquefois, le soir, elle entendait une voix cachée

A Canção de Quasímodo

sous les abat-vent du clocher chanter comme pour

(Sem rimas)

l'endormir une chanson triste et bizarre. C'étaient des vers sans

rime, comme un sourd en peut faire. 
Ne regarde pas la figure,

Jeune fille, regarde le cœur.

Le cœur d'un beau jeune homme est souvent difforme.

Il $\mathrm{y}$ a des cœurs où l'amour ne se conserve pas.

Jeune fille, le sapin n'est pas beau, N'est

pas beau comme le peuplier, Mais il garde

son feuillage l'hiver.

Hélas ! à quoi bon dire cela?

Ce qui n'est pas beau a tort d'être ;

La beauté n'aime que la beauté, Avril

tourne le dos à janvier.

La beauté est parfaite,

La beauté peut tout,

La beauté est la seule chose qui n'existe pas à demi.

Le corbeau ne vole que le jour,

Le hibou ne vole que la nuit,

Le cygne vole la nuit et le jour

(HUGO, 1904, p.320)
Não olhes só figura,

Vê coração, formosa!

Muito moço bonito o tem disforme.

Outros há, onde amor dura um só dia.

Não é belo o pinheiro

Como o álamo frondoso;

Mas conserva a folhagem pelo inverno.

Ah! mas por que estou dizendo eu isto?

O que belo não é, viver não deve;

Beleza tão somente ama Beleza;

Costas só tem Abril para Janeiro.

A beleza é perfeita,
Pode tudo a beleza;

Só beleza não há, partida ao meio.

Voa de dia o corvo,

O mocho voa à

noite;

Noite e dia, porém, o cisne

voa.

(TEIXEIRA, 1885, p. 485).

Se o organizador Múcio Teixeira considera esta "uma das produções mais curiosas de V. Hugo", talvez seja porque a canção imiscuída no terceiro capítulo do livro nono de Notre-Dame de Paris é possivelmente o único "poema" em verso livre de um autor conhecido por encarnar como poucos o verso metrificado tradicional da poesia oitocentista: "Hugo, em sua tarefa misteriosa, reduziu toda a prosa, filosofia, eloquência, história a versos, e, como era o verso em pessoa, confiscou de quem pensa, discursa ou narra, quase o direito de se enunciar" (MALLARMÉ, [201-], p. 1). Tanto é assim que 
a ausência de rimas tem de ser justificada, dentro da lógica diegética do romance, pelo fato de se tratar de um personagem surdo: "Eram versos sem rima, como um surdo pode fazer" (HUGO, 1904, p. 320, tradução nossa). Nesse sentido, é interessante comparar a obra poética tout court que Victor Hugo produzia nesse período com essa curiosa canção. A título de exemplo: em Les Feuilles d'Automne, publicado no mesmo ano que Notre-Dame de Paris, todos os quarenta poemas são metrificados e rimados, com predominância do verso alexandrino. Num contexto em que a concepção compartilhada do que devia ser a alta poesia prescrevia padrões metrorrímicos rígidos, é apenas em uma produção ancilar, concebida como parte de um romance, que Hugo se permite algo que certamente lhe parecia canhestro, mas que se tornaria comum na poesia ocidental dali a algumas décadas. Mutatis mutandis, faz pensar no uso provavelmente satírico ${ }^{14}$ por Mozart da politonalidade em Ein musikalischer Spaß (K. 522), certamente sem se dar conta de que antecipava recursos que a música moderna utilizaria de forma séria.

Por fim, cabe ainda ressaltar outra curiosidade: o aparente desapreço de Victor Hugo pela música não impediu que muitas de suas obras tenham sido adaptadas em produções de teatro musical. Se algumas dessas adaptações dispensam apresentação (como as óperas Rigoletto de Verdi e La Gioconda de Ponchielli, baseadas nas peças Le roi s'amuse e Angelo, tyran de Padoue, bem como o musical Les Misérables, de Claude-Michel Schönberg e Alain Boublil), muitas outras são menos conhecidas. É o caso de algumas óperas baseadas nas quatro obras que serviram de fonte às traduçõespoemas das Hugonianas aqui citadas. Marie Tudor foi objeto de ao menos três adaptações para a ópera: Maria, regina d'Inghilterra (1843) de Giovanni Pacini, The Armourer of Nantes (1863) de Michael William Balfe e Marie Tudor (1879) de Carlos Gomes; Ruy Blas foi base para uma ópera homônima de Filippo Marchetti de 1869; o romance Bug-Jargal foi base de uma ópera composta pelo paraense José Cândido da Gama Malcher durante o auge do ciclo da borracha (1890); já a adaptação do romance Notre-Dame de Paris, a ópera

\footnotetext{
14 “[...] A good-humored parody of bad music, in a vein Leopold would have liked." (SADIE, 1999)
} 
Esmeralda (1836) de Louise Bertin, teve o libreto escrito pelo próprio Victor Hugo, um processo de derivação textual classificável como uma espécie de "autotradução interartística" (REIS, 2019, p. 25). Assim, a despeito do que o próprio autor parecia pensar sobre essa forma de arte, sua obra se mostrou matéria-prima extremamente profícua para a música.

\section{Referências}

BESNIER, Patrick. L'abcdaire de Victor Hugo. Paris: Flammarion, 2002.

CANDIDO, Antonio. Literatura e Sociedade. Rio de Janeiro: Ouro Sobre Azul, 2019.

DIAS, Antônio Gonçalves. Últimos cantos. Londrina: Redacional, 2016.

EZUST, Emily. À quoi bon entendre. [S.1.]: The Liedernet Archive, 2014. Disponível em: https://bit.ly/2Ikzv2z. Acesso em: 6 dezembro 2019.

. Para qué escuchar. [S.1.]: The Liedernet Archive, 2014. Disponível em: <https://bit.ly/34WqAQQ>. Acesso em: 6 dezembro 2019.

HUGO, Victor. Ruy Blas. Bruxelas: Société Belge de Librarie, 1839.

. Bug-Jargal. Paris: Ollendorf, 1910.

Bug-Jargal: o libertador negro. Tradução de Adolfo de Bezerra de Menezes Neto. Salvador: Livraria Progresso Editora, 1947.

Marie Tudor: drame en trois actes. Paris: L'Arche, 1955.

HUGONIANAS. Diário Português, Rio de Janeiro, 14 de agosto de 1885, Ano 1, n. 274, p. 3.

MAGALHÃES JUNIOR, Raimundo. Antologia de poetas franceses. Rio de Janeiro: Tupi, 1950.

MALLARMÉ, Stéphane. Crise de verso. Tradução Luiz Carreira e Álvaro Faleiros. [S.1.]: [201-].

MONTES, Raphael. Neologismos indispensáveis e barbarismos dispensáveis. O Globo, 2017. Disponível em: https://oglobo.globo.com/cultura/neologismos-indispensaveis-barbarismosdispensaveis-21050042 . Acesso em: 5 dezembro 2019.

PAMBOUKIAN, Mateus Roman. Bug-Jargal: Hipertextualidade e transposição de gênero no romantismo brasileiro. 2019. Dissertação (Mestrado em Letras) - Faculdade de Filosofia, Letras e Ciências Humanas, Universidade de São Paulo, São Paulo, 2019. 
REIS, Dennys da Silva. Victor Hugo, tradutor interartístico no século XIX. Tese (Doutorado em Literatura). Universidade de Brasília, Brasília, 2019. SADIE, Stanley. Wolfgang Amadeus Mozart. [S.1.]: Encyclopædia Britannica, 1999. Disponível em: $<$ https://www.britannica.com/biography/Wolfgang-Amadeus-Mozart>. Acesso em: 22 maio 2019.

SECHIN, Antonio Carlos. João Cabral: a poesia do menos. 2 ed. Rio de Janeiro: Topbooks, 1999.

TAVARES BASTOS, Cassiano. Versões poéticas brasileiras de Victor Hugo. Petrópolis: Artes Gráficas, 1952.

TEIXEIRA, Múcio. Hugonianas. Ed. fac-sim. Rio de Janeiro: Imprensa Nacional, 1885.

\section{Resumo}

Este artigo discute a relação entre tradução e música a partir de cinco traduções em português (feitas por Rozendo Moniz, Amália Figueiroa, Félix da Cunha, João de Deus e Rozendo Moniz) de trechos de duas peças de Victor Hugo: Marie Tudor e Ruy Blas. Os dois excertos dramáticos parecem ter se tornado conhecidos em virtude de versões musicadas. A seguir, discute-se a contradição entre o aparente desapreço pessoal de Victor Hugo pela música e o frequente recurso à canção em suas peças e romances.

Palavras-chave: Tradução; Música; Romantismo; Victor Hugo.

\section{Résumé}

Cet article examine le rapport entre la traduction et la musique à partir de cinq traductions en portugais (faites par Rozendo Moniz, Amália Figueiroa, Félix da Cunha, João de Deus et Rozendo Moniz) d'extraits de deux pièces de Victor Hugo: Marie Tudor et Ruy Blas. Les deux extraits dramatiques semblent être devenus connus grâce à des adaptations musicales. Ensuite, nous discutons de la contradiction entre l'apparent mépris personnel de Victor Hugo envers la musique et le recours fréquent à la chanson dans ses pièces et romans.

Mots-clés: Traduction; Musique; Romantisme; Victor Hugo. 